\title{
Kas Hipertrofisine Güncel Bakış: Sarkomerojenez
}

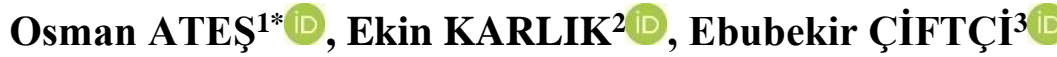 \\ ${ }^{1}$ İstanbul Üniversitesi-Cerrahpaşa, İstanbul, Türkiye \\ ${ }^{2}$ Altınbaş Üniversitesi, İstanbul, Türkiye \\ ${ }^{3}$ İstanbul Gelişim Üniversitesi, İstanbul, Türkiye
}

Derleme

Gönderi Tarihi: 24.06.2021
Kabul Tarihi: 30.12 .2021
DOI:10.47778/ejsse.957282

Online Yayın: 31.12.2021

\section{$\ddot{O} \mathbf{z}$}

Egzersize bağlı iskelet kası hipertrofisinin doğası, günümüzde hâlâ tartışmalı bir olgu olarak karşımıza çıkmaktadır. Kas hipertrofisi ölçüm yöntemleri ve kullanılan antrenman metotları gibi sürecin merkezinde yer alan çeşitli faktör ve limitasyonlar, geçmişte hipertrofik adaptasyon ve mekanizmaların doğru bir şekilde tanımlanmasına engel olmuştur. Spor biliminde yaşanan yenilik ve gelişmelerle birlikte çeşitli antrenman yöntemlerinin farklı ölçüm teknikleriyle karşılaştırıldığı uzun vadeli çalışmalar, önceki kaynaklarda yer alan hipertrofi tanımlamalarının doğruluğu konusunda şüphe uyandırmaktadır. Bu tanımlamalarla ilgili dikkat çeken en büyük eksiklik ise serial hipertrofi olgusuyla ilgilidir. Bu açıdan bu derleme, iskelet kası hipertrofisini etkileyen birçok faktörü inceleyerek bu faktörlerin serial hipertrofi üzerindeki etkilerini derlemeyi amaçlamaktadır. Bu derleme ile, hipertrofi tanımı ve hipertrofik adaptasyonlara literatür eşliğinde yeni ve güncel bir yaklaşım getirilmeye çalışılmıştır. Bu doğrultuda, 1969 ve 2020 yıları arasında yapılmış 62 çalışma ve kaynak taranmıştır. Sonuç olarak, tam hareket açıklığı, eksantrik antrenmanlar ve hızlı eksantrik antrenmanların, lif ve fasikül uzunluğundaki artışlar kapsamında daha fazla serial hipertrofiye neden olduğu, kısmi hareket açıklığı, konsantrik antrenmanlar ve yavaş eksantrik antrenmanların ise lif çapında daha fazla artışlar ortaya koyduğu vurgulanmıştır. Araştırmalar, direnç eğitimi dönemlerinde kas lifi hipertrofisi ile farklı morfolojik adaptasyonların ortaya çıkabileceğini göstermektedir.

Anahtar kelimeler: Hipertrofi, İskelet kası, Sarkomerojenez

\section{Current View on Muscle Hypertrophy: Sarcomerogenesis}

\begin{abstract}
The nature of exercise induced skeletal muscle hypertrophy is still a controversial phenomenon today. Various factors and limitations at the center of the process, such as muscle hypertrophy measurement methods and the training methods used, have prevented the correct definition of hypertrophic adaptation and mechanisms in the past. Along with the innovations and developments in sports science, long-term studies comparing various training methods with different measurement techniques raise doubts about the accuracy of hypertrophy definitions in previous sources. The largest lack of these definitions is related to the phenomenon of serial hypertrophy. In this respect, this review aims to examine many factors affecting skeletal muscle hypertrophy and to compile the effects of these factors on serial hypertrophy. In this review, a new and up-to-date approach to the definition of hypertrophy and hypertrophic adaptations has been tried to be brought together with the literature. In this direction, 62 studies and resources made between 1969 and 2020 were researched. As a result, it was emphasized that full range of motion, eccentric training and fast eccentric training caused more serial hypertrophy within the scope of increases in fiber and fascicle length, while partial range of motion, concentric training and slow eccentric training caused greater increases in fiber diameter. Research shows that different morphological adaptations may occur with muscle fiber hypertrophy during resistance training periods.
\end{abstract}

Keywords: Hypertrophy, Skeletal muscle, Sarcomerogenesis

\footnotetext{
*Sorumlu Yazar: Osman ATEŞ, E-posta: osman-ates@ hotmail.com
} 


\section{GİRIȘ}

İskelet kası hipertrofisini maksimize etmekle ilgili birçok faktörü kavramak için, vücudun egzersiz stresine nasıl tepki verdiğine ve uyum sağladığına dair temel bilgiye sahip olmak son derece önemlidir. Hem literatürde hem de spesifik kaynaklarda iskelet kası hipertrofisi üzerine çeşitli tanımlar yer almaktadır. Örneğin, McDonagh ve Davies (1984) ile Jones, Rutherford ve Paerker’a (1989) göre iskelet kası liflerinin cross-sectional alanında (CSA) artış, lif hipertrofisi olarak adlandırılmakta ve genellikle uzun vadeli kuvvet antrenmanlarında birincil adaptasyon olarak kabul edilmektedir. Benzer şekilde, Ulusal Kuvvet ve Kondisyon Birliği de (2016) hipertrofiyi antrenman sonrası kas lifi CSA artışı olarak tanımlamaktadır.

Sarkoplazmik hipertrofi adı verilen başka bir olgunun da iskelet kası boyutu artışlarına etki ettiği düşünülmektedir. Zatsiorsky ve Kraemer'e (2020) göre, kas liflerinin sarkoplazmik hipertrofisi, hücre büyümesine ve ozmotik gradientlerin korunmasına bağlı olarak boyut artırıcı etkilere katkıda bulunan sarkoplazma büyümesi ile karakterizedir. Schoenfeld (2020) ise sarkoplazmik hipertrofiyi çeşitli kontraktil olmayan elemanlarda (kollajen, organeller) ve sıvıda antrenman kaynaklı bir artış olarak tanımlamıştır. Sarkoplazmik hipertrofinin fonksiyonelliği ve kontraktil hipertrofiden bağımsız bir şekilde gerçekleşip gerçekleşmediğine dair yetersiz kanıtlar bulunmaktadır (Burd vd., 2010; Haun vd., 2019). Yapılan çalışmaların çoğunluğu hipertrofiyi kas lifinin enine kesit alanındaki artışlar olarak tanımlarken, hipertrofik süreçlerde aslında lif ve fasikül uzunluğunun artışından bahseden çalışmalar da vardır (Valatamos, 2018). Bu çalışma ile literatürün analizi yapılarak iskelet kası hipertrofisine yeni bir bakış açısı getirme ve iskelet kası hipertrofisini maksimize etmek isteyen bireyler için öneriler sunma amaçlanmaktadır. İskelet kası hipertrofisinin tanım ve adaptasyonlarının spor bilimlerindeki mevcut konumu ele alındığında, sporcularda hipertrofi maksimizasyonu açısından daha fazla araştırmaya ihtiyaç duyulmaktadır. Bu derleme ile, hipertrofi tanımı ve hipertrofik adaptasyonlara literatür eşliğinde yeni ve güncel bir yaklaşım getirilmeye çalışılmıştır. Bu doğrultuda, 1969 ve 2020 yıları arasına yapılıış 62 çalışma ve kaynak taranmıştır.

\section{Sarkomerojenez Kavramı ve Etkileyen Faktörler}

Sarkomerlerin bir lif içinde sıralı olarak uç uca eklenmesi olarak tanımlanan sarkomerojenez, bir diğer ifade şekliyle serial ipertrofi, geçmişte hem in vitro hem de in vivo modeller üzerinde çoğunlukla hayvan çalışmalarında kapsamlı bir şekilde çalışılmıştır ve hem statik hem de dinamik kas hareketleri üzerinde derin bir etkiye sahip olduğu görülmüştür (Burkholder vd., 2001; Cox vd., 2000; Goldspink vd., 1974; Griffin vd., 1971; De Deyne vd., 2000; Hofmann vd., 1980; Kelly vd., 1969). Serial hipertrofinin ve dolayısıyla sarkomerojenezin ilk inceleme alanları arasında uzuvların immobilizasyonu yer almaktadır. Kasların, mevcut miyofibrillerin uçlarına seri olarak sarkomerler ekleyerek veya tam tersi seri sarkomer sayısını azaltarak yeni bir fonksiyonel uzunluğa adapte olduğu uzun zamandır bilinmektedir (Tabary vd., 1972; Dix vd. ,1990; Griffin vd., 1971; Williams ve Goldspink, 1971). Örneğin Tabary vd. (1972), kedilerin soleus kasları üzerinde yaptıkları çalışmada, ilgili uzuvların farklı uzunluklarda immobilizasyon etkisini incelemiş ve uzun pozisyonda alçıya alınan kaslarda normal kaslara göre $\% 20$ daha fazla seri 
Ateş, O., Karlık, E. ve Çiftçi, E. (2021). Kas hipertrofisine güncel bakış: Sarkomerojenez. Avrasya Spor Bilimleri ve Ĕ̈itim Dergisi, 3(2), 156-168.

sarkomer sayısı, kısa pozisyonda alçıya alınan kaslarda ise normal kaslara göre \%40 daha az seri sarkomer sayısı bulmuşlardır. Benzer şekilde Goldspink vd. (1974), kedilerin soleus kasları üzerinde yaptıkları 4 haftalık çalışmada, immobilizasyon sırasında uzun kas boyunun seri olarak sarkomer sayısında \%25 lik bir artış meydana getirdiğini, kısa kas boyunun ise seri sarkomer sayısında \%35'lik bir azalma meydana getirdiğini tespit etmişlerdir. Ayrıca, immobilizasyonu takiben bağ dokusunun yeniden yapılanması (remodelling), farelerde, sıçanlarda, tavşanlarda ve kedilerde de birçok kez gösterilmiştir (Tabary vd., 1976; Goldspink, 1985; Tardieu vd., 1977; Tardieu vd.,1982; Williams ve Goldspink, 1984). Bununla birlikte, yeniden yapılanmanın hem oluşumunun hem de boyutunun, bağ dokusu tipine (seri elastik eleman ve/veya paralel elastik eleman), cinse, yaşa, immobiizasyon sırasındaki kas uzunluğuna ve immobilizasyon süresine bağlı olarak değiştiği görülmektedir.

İmmobilizasyona benzer şekilde stretching uygulamalarının da hipertrofik adaptasyonlar üzerine etkileri çeşitli çalışmalar tarafından incelenmiştir. Genel olarak bu çalışmalar hem kas aktivasyonu varlı̆̆ında hem de kas aktivasyonunun ortadan kaldırıldığ 1 denerve kaslarda pasif stretching uygulamasının hipertrofi meydana getirdiğini göstermiştir (Sola vd., 1973). Ayrıca stretching uygulamalarının seri sarkomer sayısında artışa neden olduğu hem hayvanlar hem de insanlar üzerinde yapılan çalışmalarda da bildirilmiştir (Cox vd., 2000; De jaeger, Joumaa ve Herzog, 2015; Simpson, Kim, Bourcet, Jones ve Jakobi, 2017). Örneğin Cox vd. (2000) tarafindan yapilan bir çalışma, tavşanların latissimus dorsi kasında 3 haftalık statik stretching ile $\% 25$ seri sarkomer artış1 bildirmiştir. Simpson vd. (2017) tarafından insanlar üzerinde yapılan bir çalışmada ise stretching uygulamasının, kas tendon kavşağında $\% 25$, kas gövdesinde ise $\% 5.1$ fasikül uzunluğu artış1 meydana getirdiği bildirilmiştir.

Konu egzersiz fizyolojisi olduğunda, seri sarkomer sayısı modülasyonu şimdiye kadar ihmal edilen bir konu olmuştur ve yalnızca son zamanlarda egzersiz protokolleri bağlamında araştırılmıştır (Morgan ve Proske, 2004). Seri sarkomer sayısının egzersize bağlı modülasyonunun doğrudan kanıtı, ilk olarak koşu bandında antrene edilen sıçanlarda postural diz ekstansörü olarak bilinen vastus intermedius kaslarında görülmüştür (Lynn ve Morgan, 1994; Lynn, Talbot ve Morgan, 1998). Kasılma tipine bağlı ayrımsal seri sarkomer sayısı adaptasyonu, in vivo olarak yokuş yukarı ve yokuş aşağı çalıştııılan sıçanların vastus intermedius ve vastus lateralis kas lifi dinamiklerinin ölçülmesiyle sonraki yıllarda yapılan müteakip çalışmalarla da doğrulanmıştır (Butterfield, Leonard ve Herzog, 2005). Buna göre, yokuş yukarı koşularda meydana gelen konsantrik kasılmalar için kısa kas uzunlukları, seri olarak sarkomer sayısında azalmaya neden olurken, yokuş aşağı koşularda meydana gelen eksantrik kasılmalar için uzun kas uzunlukları, seri olarak sarkomer kazanımı ile sonuçlanmıştır (Butterfield vd., 2005). Bu bulguları destekleyen yakın tarihli çalışmalar olduğu gibi, yine fareler üzerinde yapılan ve yokuş yukarı yürüyüşlerde seri olarak sarkomer sayısında azalma görülmesine rağmen, yokuş aşağı yürüyüsş protokollerinde seri sarkomer artışı bildirilmeyen çalışmalar da vardır (Chen vd., 2020; Morais vd., 2020). 
Ateş, O., Karlık, E. ve Çiftçi, E. (2021). Kas hipertrofisine güncel bakış: Sarkomerojenez. Avrasya Spor Bilimleri ve Ĕ̈itim Dergisi, 3(2), 156-168.

\section{Sarkomerojenezin Oluşum Nedenleri}

Sarkomerojenez veya diğer bir deyişle lif içinde seri olarak sarkomerlerin eklenmesi konusunda çeşitli hipotezler öne sürülmüş̧ür. Bunlar arasında en bilineni sarkomerojenezin yaralanmalara karşı koruyucu bir strateji olarak meydana geldiği üzerinedir (Brockett vd., 2001; Brughelli ve Cronin, 2007). Bu yaklaşımda eksantrik antrenmanların, eksantrik egzersizlerden sonra kas içi yaralanmaların fazla olması nedeniyle sarkomerlerin seri olarak eklenmesine neden olabileceği öne sürülmüştür (Armstrong vd,1983; Friden, vd., 1983; Lieber vd.,1991; Wood vd., 1993). Bu hipoteze göre sarkomerojenezin meydana gelmesi ile kas lifleri eklem hareket açıklığı boyunca uzamayla ilişkili zorlanmalara maruz kalmamakta ve bu da kası makro hasardan korumaktadır (Brockett vd., 2001).

Sarkomerojenez oluşumu ile iç içe geçmiş bir başka mekanizma da tekrarlı aktivite etkisi (repeated bout effect) ile ilgilidir. Alışıın olunmadık türde bir eksantrik egzersiz ile bir kas antrene edildiğinde bu durumun genelde ağrı ve yaralanmaya neden olduğu kabul edilmektedir (Lieber ve Friden, 2002; Lund vd., 1998; Smith, 1991). Tipik olarak eksantrik egzersizi izleyen bu ağrı süreci, gecikmiş kas ağrısı (DOMS) olarak adlandırılmaktadır (Lieber ve Friden, 2002). Eksantrik egzersizlere uzun süre maruz kalmanın DOMS belirtilerini ve semptomlarını azalttığı ve nihayetinde de ortadan kaybolmasına neden olduğu kabul edilmektedir (McHugh vd., 1999). Nitekim, Seynnes ve ark. (1985) tarafından yapılan bir çalışmada, 35 günlük yüksek şiddetli bir direnç antrenman programından sonra, rekreasyonel olarak aktif olan bir grup erkek ve kadında fasikül uzunluğunda \% 9.9'luk bir artış bildirilmişsir. Blazevich ve ark. (2007) tarafindan yapılan bir takip çalışmasında ise fasikül uzunluğundaki değişikliklerinin direnç antrenmanlarında ilk 5 haftayla sınırlı kaldığı ve oluşan adaptasyonların bu süreden sonra devam etmediği gösterilmiştir. $\mathrm{Bu}$ sonuçlar tekrarlı aktivite etkisi kapsamında sarkomerojenezin yaralanmalara karşı koruyucu bir mekanizma olabileceği görüşünü kuvvetlendirmektedir. Bununla birlikte eksantrik kasılmalarla oluşan kas hasarının kas liflerinin yırtılmasıyla meydana geldiği argümanı da tartışmalıdır. Araştırmalar kas hasarının mekanik bir nedenden ziyade biyokimyasal bir etkiye bağlı olarak meydana gelebileceğini göstermiştir. Buna göre kas hasarına daha çok hücre içi kalsiyum iyonlarının birikimi neden olmaktadır (Allen vd., 2005). Kemirgenler üzerinde yapılan bazı çalışmalarda, gerilimle aktive olan iyon kanallarını bloke etmenin, eksantrik kasılmaların neden olduğu kas lifi hasarı miktarını önemli ölçüde azalttığının gösterilmesi bu yaklaşıma katkı sağlamaktadır (Hayao vd., 2018). Ek olarak hasarın genellikle egzersizden günler sonra pik seviyeye ulaşması, süreçte mekanik bir etkiden ziyade biyokimyasal etkilerin daha gerçekçi olabileceğini de göstermektedir (Yu vd., 2004). Bu hipotezlerin doğrulanması için daha fazla sayıda çalışmaya ihtiyaç vardır. Görüldüğü üzere iskelet kası liflerinde sarkomerojenez olgusu üzerinde hem in vivo ve in vitro modellerde hem de insanlar ve hayvanlarda yapılan pek çok çalışma, uzuvların immobilizasyonu, statik stretching ve kas kasılması türüne bağlı olarak kas liflerinin boyunun uzayabildiğini göstermektedir. Ancak bu yaklaşımlardan hiçbiri tam anlamıyla egzersiz protokolleri bağlamında hipertrofi maksimizasyonu açısından konuyu ele almamaktadır. Bununla birlikte, literatürde konuya özgü yapılmış çalışmalar 1şığında bu duruma açıklık getirebilecek bir model oluşturabilmek mümkün görünmektedir. Hipertrofik bir bakış açısıyla 
Ateş, O., Karlık, E. ve Çiftçi, E. (2021). Kas hipertrofisine güncel bakış: Sarkomerojenez. Avrasya Spor Bilimleri ve Ĕ̈itim Dergisi, 3(2), 156-168.

sarkomerojenez yoluyla serial hipertrofi elde edebilmek için güncel yaklaşımlar ve direnç antrenmanı değişkenlerinin rolü kapsamındaki örnek model aşağıda yer almaktadır.

Genel olarak hipertrofiye etki ettiği düşünülen mekanik gerilim, metabolik stres ve kas hasarı olmak üzere üç ayrı mekanizma bulunmaktadır fakat hipertrofi için araştırmalarca desteklenmiş ve üzerinde en fazla fikir birliği bulunan uyarıcı mekanizma mekanik gerilim gibi görünmektedir (Schoenfeld, 2010; Schoenfeld, 2012). Mekanik gerilim, integrin gibi hücre zarında bulunan mekanosensör isimli yapılar tarafından algılanarak mekanotransüksiyon isimli süreçte hipertrofik adaptasyonlara dönüştürülmektedir (Schoenfeld, 2010). Yeni çalışmalar titin molekülünü de hipertrofik süreçlerde rol oynayan primer bir mekanosensör sınıfına dahil etmiştir (Van der Pijl vd., 2018). Mekanik gerilim, lifin kendisi tarafindan üretilmelidir ancak bahsi geçen bu üretim, ya aktif kontraksiyon ya da gerilime karşı pasif bir dirençle üretilebilmektedir (Goldspink, 1999). Kas lifi tarafindan deneyimlenen mekanik gerilim kas lifinin pasif elemanları tarafindan daha fazla üretildiğinde (titin molekülü de dahil olmak üzere lifin yapısal parçaları), lifin temel olarak yeni sarkomerler ekleyerek boyunu artırdığı görülmektedir. Bu etki, kas lifi uzunlamasına bir şekilde deforme olurken, üzerine uygulanan gerilimi (stretch) algılayan titin ile uyarılabilmektedir (Krüger ve Kötter, 2016). Tersine, kas lifi tarafından deneyimlenen mekanik gerilim aktif elemanlar tarafından daha fazla üretildiğinde (aktin ve miyozin çapraz köprüleri) ise, lifin esas olarak yeni miyofibriller ekleyerek çapını artırdığı görülmektedir. Bu etki ise, kas lifini transvers yönde deforme eden aktin-miyozin çapraz köprüleri oluştuğunda meydana gelen ve kas liflerinin dişa doğru taşmasıyla uyarılabilmektedir. Görüldüğü üzere mekanik gerilimin ne kadarının aktif veya pasif kuvvetler tarafından üretildiğini belirleyerek direnç antrenmanı değişkenlerini buna göre modifiye etmek, serial hipertrofi elde edebilmek adına son derece önemlidir. Bu faktörlere baktığımızda ise, pasif ve aktif kuvvetlerin genel anlamda mekanik gerilime olan katkısının; kasın uzunluğu, kasılma türü ve uzama hızı ile belirlendiği görülmektedir.

\section{Sarkomerojenezde En Fazla Etkisi Olan Egzersiz Türleri}

Kas uzunluğu kapsamında ele alındığında, daha geniş eklem hareket açıklıkları (ROM) içeren egzersizler kullanılarak yapılan direnç antrenmanları, pasif elemanlardan gelen mekanik gerilim oranını artırmaktadır, çünkü kasın yapısal elemanları ve kas lifleri belirli bir uzunluğa ulaştıktan sonra gerilmektedir. Yaygın inanışın aksine, hem tam ROM hem de kısmi ROM ile gerçekleştirilen konsantrik antrenmanlar, hipertrofi ölçümü kas hacmine yönelik yapıldığında kas hacminde benzer değişiklikler içerse de, yapısal adaptasyonlar farklılık göstermektedir. Örneğin, Valamatos vd. (2018) tarafından 19 erkek katılımcı ile yürütülen bir çalışmada bu durum açıkça gösterilmiştir. Tam ROM ve kısmi ROM'lardan oluşan programların karşılaştırıldığı çalışmada yapılan ölçümlerde her iki koşulda da kas hacminde benzer artışlar görülse de, hipertrofi türü koşullar arasında farklılık göstermiştir. Çalışmaya göre, tam ROM ile yapılan antrenmanlar esas olarak fasikül uzunluğundaki artışlar ile hipertrofiye neden olurken, kısmi ROM ile yapılan antrenmanlar çoğunlukla kesitsel alanda artışlara neden olmuştur. 
Ateş, O., Karlık, E. ve Çiftçi, E. (2021). Kas hipertrofisine güncel bakış: Sarkomerojenez. Avrasya Spor Bilimleri ve Ĕ̈itim Dergisi, 3(2), 156-168.

Fonksiyon gören sarkomer uzunlukları, pasif elamanların mekanik gerilime olan katkısını belirleyen bir başka önemli faktördür. Her ne kadar tam hareket açılığının kullanıldığ egzersizlerde serial hipertrofide üstün artış bildiren çalışmalar olsa da, bu kapsam fonksiyon gören sarkomer uzunlukları ile sınırlı görünmektedir. Çalışmalar, her bir major kasın sarkomerlerinin hareket açıklığı boyunca aynı uzunluklara ulaşamadığını, dolayısıyla titinin sert segmentinin her bir kasta aynı düzeyde pasif mekanik gerilim üretemediğini göstermektedir (Cutts, 1988). Nitekim Valatamos vd.'nin (2018) çalışması ile tutarlı olarak çalışmalar, vastus laterialis kasının sarkomerlerinin uzunluk-gerilim ilişkisi grafiğinde alçalan eğriye ulaşabildiklerini gösterirken, triceps brachii long head gibi pek çok kas söz konusu olduğunda, sarkomer uzama derecesinin hareket açıklığı boyunca nispeten değişmeden kaldığını göstermektedir (Butterfield ve Herzog, 2006; Son, Indresano, Sheppard, Ward ve Lieber, 2018).

Kasılma türü kapsamında ele alındığında, eksantrik antrenmanların, pasif elemanlardan gelen mekanik gerilim oranını artırdığı görülmektedir. Çünkü kas lifi uzamaya başladığında titin aktive olmakta ve otomatik olarak kuvvet üretimine katkıda bulunmaya başlamaktadır. Titin, küçük bir N2A segmenti ile birbirlerinden ayrılan sıralı halde iki eleman içermektedir (Ig bölgeleri ve PEVK segmenti) (Hessel, Lindstedt ve Nishikawa, 2017). Pasif olarak uzatıldığında, oldukça elastik olan Ig bölgelerinin uzunluğu artmakta ve bu da gerilime karşı sadece küçük bir miktar direnç sağlamaktadır. Aktif olarak uzatıldığında ise, N2A aktin filamentlerine bağlanmaktadır ve bu da, titinin uzunluğundaki değişimin ne kadarının Ig bölgelerinin uzatılmasıyla elde edilebileceği konusunda limitasyon yaratmaktadır. Sonuç olarak, çok daha sert olan PEVK segmentinin uzaması, gerilime karşı büyük miktarda pasif direnç sağlamaktadır. Bu durum yalnıca aktif uzamanın olduğu eksantrik kontraksiyonlarda geçerlidir (Schoenfeld, Ogborn, Vigitosky, Franchi ve Krieger, 2017).

Geçmiş yıllarda, eksantrik antrenmanların, konsantrik veya geleneksel direnç antrenmanlarından daha fazla kas hipertrofisi sağlayabileceğine inanılmaktaydı. Günümüzde ise programlarda eşit hacim veya eşit antrenman yükü sağlandığında, hem eksantrik hem de konsantrik direnç antrenmanlarından sonra meydana gelen hipertrofi miktarının oldukça benzer olduğu uzmanlarca yaygın bir şekilde kabul görmektedir (Schoenfeld vd., 2017). Örneğin Schoenfeld vd. (2017) tarafından yapılan ve 15 çalışmanın dahil edildiği bir meta analizde, eksantrik kassal eylemlerin konsantrik eylemlere kıyasla biraz daha fazla hipertrofi meydana getirdiği ancak sonuçların istatistiksel anlamlılığa erişmediği gösterilmiştir (Schoenfeld vd., 2017). Daha da önemlisi, güncel araştırmalar, eksantrik ve konsantrik direnç antrenmanlarının kas hacminde benzer artışlar sağlamasına rağmen, eksantrik antrenmanların esas olarak fasikül uzunluğunu artırırken, konsantrik antrenmanların ise kas kesit alanını artırdığını göstermektedir (Franchi vd., 2015).

Serial hipertrofi konusunda antrenman değişkenleri modifikasyonu konusunda ele alınabilecek diğer bir değişken ise kas liflerinin uzama hızıdır. Uzama hızı sırasıyla pasif ve aktif elemanların ürettiği kuvvet oranını etkilemektedir. Daha yüksek hızlarda aktin-miyozin çapraz köprülerinin ayrılma hızı daha fazla olduğu için aktif elemanlardan gelen mekanik gerilim oranı azalmaktadır, 
Ateş, O., Karlık, E. ve Çiftçi, E. (2021). Kas hipertrofisine güncel bakış: Sarkomerojenez. Avrasya Spor Bilimleri ve Ĕ̈itim Dergisi, 3(2), 156-168.

dolayısıyla bu da üretilen aktif kuvvet miktarını azaltmaktadır. Öte yandan, titinin viskoelastik özellikleri ve kas lifinin uzamaya dirençli diğer yapısal elemanları nedeniyle pasif elemanlardan gelen mekanik gerilim oranı artmaktadır (Rehorn, Schroer ve Blemker, 2014). Sonuç olarak, hızlı eksantrik antrenmanlar, fasikül uzunluğunda, yavaş eksantrik antrenmanlara göre daha fazla artış ortaya koymaktadır (Alegre vd., 2006; Blazevich vd., 2013). Yavaş eksantrik antrenmanlar ise daha çok kas kesit alanında artışa neden olmaktadır (Sharifnezhad, 2014).

\section{TARTIŞMA VE SONUÇ}

Araştırmalar, direnç eğitimi dönemlerinde kas lifi hipertrofisi ile farklı morfolojik adaptasyonların ortaya çıkabileceğini göstermektedir. Bununla birlikte, insanlar üzerinde yapılan araştırmalar farklı eğitim biçimlerinin veya eğitim süresinin morfolojik adaptasyonları nasıl etkilediği konusunda hala yetersizdir. Bu veri yetersizliğine rağmen, bu incelemenin yazılmasında nihai amaç araştırma konusuna daha fazla ilgi göstermektir. Bu tür arayışlar, serial hipertrofinin direnç eğitimi adaptasyonlarını kolaylaştırmada bir rolü olup olmadığını doğrulayacak veya çürütecektir.

Özellikle spor bilimleri alanında iskelet kası hipertrofisine yönelik hakim olan tanımlamaların aksine, hipertrofik süreçler sırasında kaslarda pek çok farklı yapısal adaptasyonların meydana geldiği açıkça görülmektedir. Bu adaptasyonların en önemlilerinden biri de, sarkomerlerin seri olarak uç uca eklenerek kas hacminde artışlar meydana getirdiği sarkomerojenez olgusudur. $\mathrm{Bu}$ süreç, hipertrofinin yalnızca kasın enine kesit alanında meydana gelen artışları değil, aynı zamanda kas lifi boyunda ve fasikül uzunluğunda artışlar olması nedeniyle özellikle önem arz etmektedir. Sarkomerojenez, diğer bir deyişle serial hipertrofi olgusunun inceleme alanları çok eskiye dayanmasına rağmen, egzersiz protokolleri bağlamında incelenmesi nispeten yenidir. Günümüzde egzersize bağlı hipertrofik adaptasyonların ardındaki temel mekanizmanın mekanik gerilim olduğu yönündeki çalışmalar doğrultusunda, kas lifinin çap veya uzunluk olarak artışlar sergileyerek hipertrofi meydana getirmesi, aktif ve pasif mekanik gerilimin doğasına bağlı görünmektedir. Buna göre, kas lifinin aktif elemanları tarafından (aktin-miyozin) üretilen mekanik gerilim, daha çok lif çapında artışlar ile hipertrofi meydana getirirken, kas lifnin pasif elemanları tarafından (titin benzeri yapılar) üretilen mekanik gerilim, daha çok lif uzunluğunda artışlar ile hipertrofi meydana getirmektedir. Literatürden elde edilen çalışmalar, pasif elemanların mekanik gerilime olan katkısının tam hareket açıklığı (Full ROM), eksantrik antrenmanlar ve hızlı eksantrik antrenmanlar ile arttığını göstermektedir. Konuya ilişkin pratik çıkarımlar yapabilmek için daha fazla çalışmaya ihtiyaç duyulmaktadır.

Çıkar Çatışması: Yazarlar herhangi bir çıkar çatışması olmadığını beyan etmelidir.

Yayın Etiği: Mevcut çalışmanın yazım sürecinde "Yükseköğretim Kurumları Bilimsel Araştırma ve Yayın Etiği Yönergesi" kapsamında bilimsel, etik ve alıntı kurallarına uyulmuş olup; toplanan veriler üzerinde herhangi bir tahrifat yapılmamış ve bu çalışma herhangi başka bir akademik yayın ortamına değerlendirme için gönderilmemiştir.

Yazar Katkı Beyanı: Yazarlar, çalışmada eşit katkı oranına sahiptir. 
Ateş, O., Karlık, E. ve Çiftçi, E. (2021). Kas hipertrofisine güncel bakış: Sarkomerojenez. Avrasya Spor Bilimleri ve Ĕ̈itim Dergisi, 3(2), 156-168.

\section{KAYNAKÇALAR}

Alegre, L. M., Jiménez, F., Gonzalo-Orden, J. M., Martín-Acero, R. \& Aguado, X. (2006). Effects of dynamic resistance training on fascicle lengthand isometric strength. Journal of Sports Sciences, 24(5), 501-508. DOI: $10.1080 / 02640410500189322$

Allen, D. G., Whitehead, N. P. \& Yeung, E. W. (2005). Mechanisms of stretch-induced muscle damage in normal and dystrophic muscle: role of ionic changes. The Journal of Physiology, 567(3), 723-735. DOI: 10.1113/jphysiol.2005.091694

Armstrong, R. B., Ogilvie, R. W. \& Schwane, J. A. (1983). Eccentric exercise-induced injury to rat skeletal muscle. Journal of Applied Physiology, 54(1), 80-93. DOI: 10.1152/jappl.1983.54.1.80

Blazevich, A. J., Cannavan, D., Coleman, D. R. \& Horne, S. (2007). Influence of concentric and eccentric resistance training on architectural adaptation in human quadriceps muscles. Journal of Applied Physiology, 103(5), 1565-1575. DOI: 10.1152/japplphysiol.00578.2007

Blazevich, A. J., Gill, N. D., Bronks, R. \& Newton, R. U. (2013). Training-specific muscle architecture adaptation after 5-wk training in athletes. Medicine \& Science in Sports \& Exercise, 35(12), 2013-2022. DOI: 10.1249/01.mss.0000099092.83611.20

Brockett, C. L., Morgan, D. L. \& Proske, U. W. E. (2001). Human hamstring muscles adapt to eccentric exercise by changing optimum length. Medicine \& Science in Sports \& Exercise, 33(5), 783-790

Brughelli, M., \& Cronin, J. (2007). Altering the length-tension relationship with eccentric exercise. Sports Medicine, 37(9), 807-826. DOI: 10.2165/00007256-200737090-00004

Burd, N. A., West, D. W. D., Staples, A. W., Atherton, P. J., Baker, J. M., Moore, D. R., ... Phillips, S. M. (2010). Low-load high volume resistance exercise stimulates muscle protein synthesis more than high-load low volume resistance exercise in young men. PLoS ONE, 5(8), e12033. DOI: 10.1371/journal.pone.0012033

Burkholder, T. J. (2001). Age does not influence muscle fiber length adaptation to increased excursion. Journal of applied physiology, 91(6), 2466-2470. DOI: 10.1152/jappl.2001.91.6.2466

Butterfield, T. A. \& Herzog, W. (2006). The magnitude of muscle strain does not influence serial sarcomere number adaptations following eccentric exercise. Pflügers Archiv- European Journal of Physiology, 451(5),688700. DOI: $10.1007 / \mathrm{s} 00424-005-1503-6$

Butterfield, T. A., Leonard, T. R. \& Herzog, W. (2005). Differential serial sarcomere number adaptations in knee extensor muscles of rats is contraction type dependent. Journal of Applied Physiology, 99(4), 1352-1358. DOI: 10.1152/japplphysiol.00481.2005

Chen, J., Mashouri, P., Fontyn, S., Valvano, M., Elliott-Mohamed, S., Noonan, A. M., ... Power, G. A. (2020). The influence of training-induced sarcomerogenesis on the history dependence of force. The Journal of Experimental Biology, jeb.218776. DOI: 10.1242/jeb.218776

Cox, V. M., Williams, P. E., Wright, H., James, R. S., Gillott, K. L., Young, I. S. \& Goldspink, D. F. (2000). Growth induced by incremental static stretch in adult rabbit latissimus dorsi muscle. Experimental Physiology, 85(2), 193-202. DOI: 10.1111/j.1469-445x.2000.01950.x

Cutts, A. (1988). The range of sarcomere lengths in the muscles of the human lower limb. Journal of anatomy, 160, $79-80$.

Dix, D. J. \& Eisenberg, B. R. (1990). Myosin mRNA accumulation and myofibrillogenesis at the myotendinous junction of stretched muscle fibers. The Journal of Cell Biology,111(5),1885-1894. DOI: 10.1083/jcb.111.5.1885. 
Ateş, O., Karlık, E. ve Çiftçi, E. (2021). Kas hipertrofisine güncel bakış: Sarkomerojenez. Avrasya Spor Bilimleri ve Ĕ̈itim Dergisi, 3(2), 156-168.

De Deyne, P. G. (2000). Formation of sarcomeres in developing myotubes: role of mechanical stretch and contractile activation. American Journal of Physiology-Cell Physiology, 279(6), C1801-C1811. DOI: 10.1152/ajpcell.2000.279.6.c1801

De Jaeger, D., Joumaa, V. \& Herzog, W. (2015). Intermittent stretch training of rabbit plantarflexor muscles increases soleus mass and serial sarcomere number. Journal of Applied Physiology, 118(12), 1467-1473. DOI: 10.1152/japplphysiol.00515.2014

Franchi, M. V., Wilkinson, D. J., Quinlan, J. I., Mitchell, W. K., Lund, J. N., Williams, J. P., ... Narici, M. V. (2015). Early structural remodeling and deuterium oxide-derived protein metabolic responses to eccentric and concentric loading in human skeletal muscle. Physiological Reports, 3(11), e12593. DOI: $10.14814 /$ phy2.12593

Friden, J., Sjöström, M. \& Ekblom, B. (1983). Myofibrillar damage following intense eccentric exercise in man. International journal of sports medicine, 4(03), 170-176. DOI: 10.1055/s-2008-1026030

Goldspink, G. (1985). Malleability of the motor system: a comparative approach. Journal of experimental biology, 115(1), 375-391. DOI: 10.1242/jeb.115.1.375

Goldspink, G. (1999). Changes in muscle mass and phenotype and the expression of autocrine and systemic growth factors by muscle in response to stretch and overload. Journal of Anatomy, 194(3), 323-334. DOI: 10.1046/j.1469-7580.1999.19430323.x

Goldspink, G., Tabary, C., Tabary, J. C., Tardieu, C. \& Tardieu, G. (1974). Effect of denervation on the adaptation of sarcomere number and muscle extensibility to the functional length of the muscle. The Journal of Physiology, 236(3), 733-742. DOI: 10.1113/jphysiol.1974.sp010463

Griffin, G. E., Williams, P. E. \& Goldspink, G. (1971). Region of longitudinal growth in striated muscle fibres. Nature New Biology, 232(27), 28-29. DOI: 10.1038/newbio232028a0

Haun, C. T., Vann, C. G., Osburn, S. C., Mumford, P. W., Roberson, P. A., Romero, M. A., ... Roberts, M. D. (2019). Muscle fiber hypertrophy in response to 6 weeks of high-volume resistance training in trained young men is largely attributed to sarcoplasmic hypertrophy. PLOS ONE, 14(6), e0215267. DOI: 10.1371/journal.pone.0215267

Hayao, K., Tamaki, H., Nakagawa, K., Tamakoshi, K., Takahashi, H., Yotani, K., ... \& Onishi, H. (2018). Effects of Streptomycin Administration on Increases in Skeletal Muscle Fiber Permeability and Size Following Eccentric Muscle Contractions. The Anatomical Record, 301(6), 1096-1102. DOI: 10.1002/ar.23770

Hessel, A. L., Lindstedt, S. L. \& Nishikawa, K. C. (2017). Physiological Mechanisms of Eccentric Contraction and Its Applications: A Role for the Giant Titin Protein. Frontiers in Physiology, 8, 1-14. DOI: 10.3389/fphys.2017.00070

Hofmann, W. W. (1980). Mechanisms of muscular hypertrophy. Journal of the Neurological Sciences, 45(2-3), 205216. DOI: $10.1016 / 0022-510 x(80) 90166-5$

Jones, D. A., Rutherford, O. M. \& Parker, D. F. (1989). Physiological changes in skeletal muscle as a result of strength training. Quarterly Journal of Experimental Physiology: Translation and Integration, 74(3), 233-256. DOI: 10.1113/expphysiol.1989.sp003268

Kelly, D. E. (1969). Myofibrillogenesis and Z-band differentiation. The Anatomical Record, 163(3), 403-425. DOI: 10.1002/ar.1091630305

Krüger, M. \& Kötter, S. (2016). Titin, a central mediator for hypertrophic signaling, exercise-induced mechanosignaling and skeletal muscle remodeling. Frontiers in physiology, 7(76),1-8. DOI: 10.3389/fphys.2016.00076

Lieber, R. L. \& Fridén, J. (2002). Morphologic and mechanical basis of delayed-onset muscle soreness. JAAOSJournal of the American Academy of Orthopaedic Surgeons, 10(1), 67-73. 
Ateş, O., Karlık, E. ve Çiftçi, E. (2021). Kas hipertrofisine güncel bakış: Sarkomerojenez. Avrasya Spor Bilimleri ve Ĕ̈itim Dergisi, 3(2), 156-168.

Lieber, R. L., Woodburn, T. M., \& Friden, J. (1991). Muscle damage induced by eccentric contractions of 25\% strain. Journal of Applied Physiology, 70(6), 2498-2507. DOI: 10.1152/jappl.1991.70.6.2498

Lund, H., Vestergaard-Poulsen, P., Kanstrup, I.L., Sejrsen, P. (1998). Isokinetic eccentric exercise as a model to induce and reproduce pathophysiological alterations related to delayed onset muscle soreness. Scand J Med Sci Sports, 8,208-215. DOI: 10.1111/j.1600-0838.1998.tb00194.x

Lynn, R. \& Morgan, D. L. (1994). Decline running produces more sarcomeres in rat vastus intermedius muscle fibers than does incline running. Journal of applied physiology, 77(3), 1439-1444. DOI: 10.1152/jappl.1994.77.3.1439

Lynn, R., Talbot, J. A., \& Morgan, D. L. (1998). Differences in rat skeletal muscles after incline and decline running. Journal of Applied Physiology, 85(1), 98-104. DOI: 10.1152/jappl.1998.85.1.98

McDonagh, M. J. N. \& Davies, C. T. M. (1984). Adaptive response of mammalian skeletal muscle to exercise with high loads. European Journal of Applied Physiology and Occupational Physiology, 52(2), 139-155. DOI: $10.1007 / \mathrm{bf00433384}$

McHugh, M. P., Connolly, D. A. J., Eston, R. G. \& Gleim, G. W. (1999). Exercise-Induced Muscle Damage and Potential Mechanisms for the Repeated Bout Effect. Sports Medicine, 27(3), 157-170. DOI: 10.2165/00007256-199927030-00002

Morais, G. P., da Rocha, A. L., Neave, L. M., Lucas, G. D. A., Leonard, T. R., Carvalho, A., ... \& Herzog, W. (2020). Chronic uphill and downhill exercise protocols do not lead to sarcomerogenesis in mouse skeletal muscle. Journal of Biomechanics, 98, 109469. DOI: 10.1016/j.jbiomech.2019.109469

Morgan, D. L. \& Proske, U. (2004). Popping sarcomere hypothesis explains stretch induced muscle damage. In Proceedings of the Australian Physiological and Pharmacological Society, 34, 19-23.

Rehorn, M. R., Schroer, A. K. \& Blemker, S. S. (2014). The passive properties of muscle fibers are velocity dependent. Journal of Biomechanics, 47(3), 687-693. DOI: 10.1016/j.jbiomech.2013.11.044

Roberts, M. D., Haun, C. T., Vann, C. G., Osburn, S. C. \& Young, K. C. (2020). Sarcoplasmic hypertrophy in skeletal muscle: A scientific "unicorn" or resistance training adaptation?. Frontiers in Physiology, 11, 816, 1-16. DOI: $10.3389 /$ fphys.2020.00816

Schoenfeld, B. (2020). Science and development of muscle hypertrophy. USA: Human Kinetics.

Schoenfeld, B. J. (2010). The mechanisms of muscle hypertrophy and their application to resistance training. The Journal of Strength \& Conditioning Research, 24(10), 2857-2872. DOI: 10.1519/jsc.0b013e3181e840f3

Schoenfeld, B. J. (2012). Does exercise-induced muscle damage play a role in skeletal muscle hypertrophy?. The Journal of Strength \& Conditioning Research, 26(5), 1441-1453. DOI: doi:10.1519/jsc.0b013e31824f207e

Schoenfeld, B. J., Ogborn, D. I., Vigotsky, A. D., Franchi, M. V. \& Krieger, J. W. (2017). Hypertrophic effects of concentric vs. eccentric muscle actions: a systematic review and meta-analysis. The Journal of Strength \& Conditioning Research, 31(9), 2599-2608. DOI: 10.1519/jsc.000000000001983

Seynnes, O. R., de Boer, M. \& Narici, M. V. (2007). Early skeletal muscle hypertrophy and architectural changes in response to high-intensity resistance training. Journal of Applied Physiology, 102(1), 368-373. DOI: 10.1152/japplphysiol.00789.2006

Sharifnezhad, A. (2014). Longitudinal adaptation of vastus lateralis muscle in response to eccentric exercise. Dissertation. Zur Erlangung des akademischen Grads. 
Ateş, O., Karlık, E. ve Çiftçi, E. (2021). Kas hipertrofisine güncel bakış: Sarkomerojenez. Avrasya Spor Bilimleri ve Ĕ̈itim Dergisi, 3(2), 156-168.

Simpson, C. L., Kim, B. D. H., Bourcet, M. R., Jones, G. R. \& Jakobi, J. M. (2017). Stretch training induces unequal adaptation in muscle fascicles and thickness in medial and lateral gastrocnemii. Scandinavian Journal of Medicine \& Science in Sports, 27(12), 1597-1604. DOI: 10.1111/sms.12822

Smith, L. L. (1991). Acute inflammation: The underlying mechanism in delayed onset muscle soreness?. Medicine and science in sports and exercise, 23(5), 542-551.

Sola, O. M., Christensen, D. L. \& Martin, A. W. (1973). Hypertrophy and hyperplasia of adult chicken anterior latissimus dorsi muscles following stretch with and without denervation. Experimental Neurology, 41(1), 76100. DOI: $10.1016 / 0014-4886(73) 90182-9$

Son, J., Indresano, A., Sheppard, K., Ward, S. R. \& Lieber, R. L. (2018). Intraoperative and biomechanical studies of human vastus lateralis and vastus medialis sarcomere length operating range. Journal of Biomechanics, 67 91-97. DOI: 10.1016/j.jbiomech.2017.11.038

Tabary, J. C., Tabary, C., Tardieu, C., Tardieu, G. \& Goldspink, G. (1972). Physiological and structural changes in the cat's soleus muscle due to immobilization at different lengths by plaster casts. The Journal of Physiology, 224(1), 231-244. DOI: 10.1113/jphysiol.1972.sp009891

Tabary, J. C., Tardieu, C., Tardieu, G., Tabary, C. \& Gagnard, L. (1976). Functional adaptation of sarcomere number of normal cat muscle. Journal de physiologie, 72(3), 277-291.

Tardieu, C., \& Tabary, J.C. \& de laTour, E.H. (1977). Comparison of the sarcomere number adaptation in young and adult animals. Influence of tendon adaptation. Journal de physiologie, 73(8),1045-55.

Tardieu, C., Tabary, J. C., Tabary, C. \& Tardieu, G. (1982). Adaptation of connective tissue length to immobilization in the lengthened and shortened positions in cat soleus muscle. Journal de physiologie, 78(2), 214-220.

Valamatos, M. J., Tavares, F., Santos, R. M., Veloso, A. P. \& Mil-Homens, P. (2018). Influence of full range of motion vs. equalized partial range of motion training on muscle architecture and mechanical properties. European Journal of Applied Physiology, 118(9), 1969-1983. DOI: 10.1007/s00421-018-3932-x

Van der Pijl, R., Strom, J., Conijn, S., Lindqvist, J., Labeit, S., Granzier, H. \& Ottenheijm, C. (2018). Titin-based mechanosensing modulates muscle hypertrophy. Journal of Cachexia, Sarcopenia and Muscle, 9(5), 947961. doi: $10.1002 / \mathrm{jcsm} .12319$.

Williams, P. E. \& Goldspink, G. (1971). Longitudinal growth of striated muscle fibres. Journal of Cell Science, 9(3), 751-767. DOI: $10.1242 /$ jcs.9.3.751

Williams, P. E. \& Goldspink, G. (1984). Connective tissue changes in immobilised muscle. Journal of Anatomy, 138(Pt 2), 343-350.

Wood, S. A., Morgan, D. L. \& Proske, U. (1993). Effects of repeated eccentric contractions on structure and mechanical properties of toad sartorius muscle. American Journal of Physiology-Cell Physiology, 265(3), C792-C800. DOI: 10.1152/ajpcell.1993.265.3.C792

Yu, J. G., Carlsson, L. \& Thornell, L. E. (2004). Evidence for myofibril remodeling as opposed to myofibril damage in human muscles with DOMS: an ultrastructural and immunoelectron microscopic study. Histochemistry and Cell Biology, 121(3), 219-227. DOI: 10.1007/s00418-004-0625-9

Zatsiorsky, V. M., Kraemer, W. J. \& Fry, A. C. (2020). Science and practice of strength training (3. Baskı). USA: Human Kinetics. 


\section{EXTENDED ABSTRACT}

\section{Current View on Muscle Hypertrophy: Sarcomerogenesis}

\section{Introduction}

To comprehend the many factors related to maximizing skeletal muscle hypertrophy, it is essential to have a foundational knowledge of how the body reacts and adapts to exercise stress. There are various definitions of skeletal muscle hypertrophy both in the literature and in specific sources. However, these definitions do not generally address the phenomenon called serial hypertrophy. Hypertrophy can occur by adding sarcomeres either in parallel or in series. In the context of traditional exercise protocols, the majority of gains in muscle mass result from an increase of sarcomeres added in parallel. An in-series increase in sarcomeres means a given muscle length corresponding to a shorter sarcomere length. An increase in serial hypertrophy is a phenomenon observed in both humans and animals. When it comes to training protocols, eccentric training, full range of motion training, and slow eccentric training seem to increase serial hypertrophy.

\section{Method}

In our current review, "Pubmed", "Scholar Google", "Sciencedirect" and "Researchgate" databases were used for the literature review, using the keywords hypertrophy, sarcomerogenesis, serial hypertrophy, in-series hypertrophy, exercise-induced muscle hypertrophy. In this direction, 62 studies and resources made between 1969 and 2020 were researched.

\section{Findings}

Although an issue that has been overlooked in the past, our findings suggest that muscle hypertrophy occurs not only in cross-sectional area but also in length. This phenomenon, which is frequently observed in stretching and immobilization applications in animal studies, also occurs in humans as a result of certain training protocols. These training protocols consist of eccentric training, full range of motion training, and fast eccentric training.

\section{Discussion and Conclusion}

Research shows that different morphological adaptations may occur with muscle fiber hypertrophy during periods of resistance training. However, human studies are still insufficient on how different training methods or training duration affect morphological adaptations. Contrary to the popular definitions of skeletal muscle hypertrophy, especially in the field of sports sciences, it is clearly seen that many different structural adaptations occur in muscles during hypertrophic processes. One of the most important of these adaptations is the phenomenon of sarcomerogenesis, in which sarcomeres are serially attached end-to-end, resulting in increases in muscle volume. Although the research areas of sarcomerogenesis, in other words serial hypertrophy, are very old, it is relatively new to examine in the context of exercise protocols. Today, in line with the studies suggesting that the main mechanism behind exercise-induced hypertrophic adaptations is mechanical tension, it seems that muscle fiber causes hypertrophy by increasing in diameter or length, depending on the nature of active and passive mechanical tension. During strength training, when the mechanical 
Ateş, O., Karlık, E. ve Çiftçi, E. (2021). Kas hipertrofisine güncel bakış: Sarkomerojenez. Avrasya Spor Bilimleri ve Ĕ̈itim Dergisi, 3(2), 156-168.

tension experienced by a fiber is produced more by the passive elements, the fiber seems to increase in volume mainly by increasing in length. In contrast, when the mechanical tension experienced by the fiber is produced more by the active elements, the fiber seems to increase in volume mainly by increasing in diameter. The contribution of passive and active force to overall mechanical tension, and therefore whether hypertrophy occurs through increases in either fiber length or diameter, is determined by the length of the muscle, the contraction mode, and the lengthening speed.

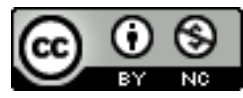

Bu eser Creative Commons Atıf-Gayri Ticari 4.0 Uluslararası Lisansı ile lisanslanmıştır. 